\title{
A última embaixada de um monarca africano no Brasil: Manoel Alves Lima, um embaixador do Reino de Onim na corte de D. Pedro I
}

Gilberto da Silva Guizelin*

Resumo: Este artigo trata da terceira embaixada do Reino de Onim ao Brasil (c. 1822-25). Enviada pelo rei Ajan e chefiada pelo Tenente Coronel Manoel Alves Lima, essa embaixada foi a última missão diplomática de um monarca africano em solo brasileiro. Ela foi ainda a única das embaixadas africanas enviadas no século XIX que obteve permissão para completar a sua missão, seguindo para o Rio de Janeiro ao encontro do imperador D. Pedro I, a quem Manoel Alves Lima apresentou o reconhecimento da independência do Império em nome de Ajan e de outros soberanos do "Continente Negro". À luz de uma documentação diplomática pouco difundida e, portanto, ainda inédita, este artigo busca reconstruir a história dessa embaixada e, por meio desta, adensar a compreensão do quadro histórico das relações africano-brasileiras.

Palavras-chave: Diplomacia. Independência. África. Brasil. Onim.

\section{Introdução}

Em 2012, realizei uma série de visitas ao Arquivo Histórico do Itamaraty (AHI), no Rio de Janeiro, com o intuito de levantar documentos para o desenvolvimento de minha pesquisa de doutorado,

" Doutorando do Programa de Pós-Graduação em História da Universidade Estadual Paulista (UNESP), Campus de Franca. Bolsista da Fundação de Amparo à Pesquisa do Estado de São Paulo (FAPESP). E-mail: guizelin.gs@gmail.com

Anos 90, Porto Alegre, v. 22, n. 42, p. 325-351, dez. 2015 
também iniciada naquele ano. Interessado nas relações nutridas entre o Império do Brasil com a Angola Colonial, no decorrer da primeira metade do século XIX, debrucei-me no exame dos papéis da antiga Secretaria de Estados dos Negócios Estrangeiros relativos à África. Numa dessas visitas, deparei-me com a Pasta 06 - Missões Especiais Estrangeiras Diversas: África, Argentina e Bolívia (18241920) ${ }^{1}$ e, intrigado pelo título e pela periodização, decidi explorá-la. Qual não foi a minha surpresa ao constatar que a missão especial vinda da África, a qual se referiam os papéis ali reunidos, era a de Manoel Alves Lima, enviado ao Rio de Janeiro pelo rei Ajan (ou Adele), do reino de Onim (conhecido por Lagos pelos ingleses, e por Eko pelos franceses), para transmitir a D. Pedro I o seu reconhecimento da independência do Brasil.

O episódio protagonizado por Manoel Alves Lima não me era desconhecido. Através da leitura das obras de Pierre Verger (1987) e de Alberto da Costa e Silva (2003 e 2005), já me haviam chegado algumas notícias sobre esse intrigante personagem. De acordo com esses autores, Alves Lima foi provavelmente um comerciante de escravos atuante na rota entre a África Ocidental e a Bahia, que "[...] usando o título de embaixador do rei de Onim e tomando-se por tenente-coronel” (VERGER, 1987, p. 284) escrevia de Salvador, em 1823, para o imperador brasileiro, solicitando permissão para seguir viagem até o Rio de Janeiro a fim de cumprir a incumbência que lhe fora confiada por Ajan e pelos demais monarcas do Golfo do Benim.

Como os objetivos da minha pesquisa eram outros, não explorei a documentação naquele momento, o que me proponho a realizar neste artigo, partindo de duas questões que surgiram naquela ocasião: teriam Verger, Costa e Silva e os demais autores que já trabalharam e que trabalham com o tema das embaixadas africanas no Brasil Setecentista e Oitocentista tido contato com essa documentação? Que informações esses papéis podem confirmar, refutar ou mesmo sugerir para o enriquecimento da literatura especializada sobre as relações bilaterais de longa duração entre o Brasil e a África?

No presente artigo tomo, portanto, como fonte principal essa documentação conservada no Itamaraty. Alguns dos papéis reunidos na pasta são duplicatas de documentos já topados por Verger e Costa 
e Silva durante suas investigações em outros fundos e arquivos. Mas ali também há uma documentação até então desconhecida, composta por meia dezena de notas e correspondências trocadas, em sua maioria, entre Luís José de Carvalho e Mello, visconde da Cachoeira e ministro dos Negócios Estrangeiros de D. Pedro I, entre 1823 e 1825, e as pessoas de Manoel Alves Lima e seu secretário particular, José Vicente de Santa Ana. Infelizmente, os papéis reunidos na pasta não contêm cabeçalhos nem números que nos permitam identificá-los nominalmente. E alguns sequer tem data. Dessa forma, quando extraída ou referenciada alguma informação da documentação, limitar-me-ei em citar o maço de sua localização no Arquivo Histórico do Itamaraty: estante 273, prateleira 1, maço 13. Por fim, quanto à metodologia de trabalho aqui adotada, a fim de contornar o caráter lacunar, escasso e fragmentário da documentação, procurei analisar e interpretar os documentos à luz da historiografia pertinente sobre a natureza e as vicissitudes das embaixadas africanas enviadas ao Brasil na transição do século XVIII para o século XIX.

Começo este texto com um exame das relações bilaterais entre o Reino de Onim e o Brasil, na virada do Setecentos para o Oitocentos, com o intuito de pontuar o contexto em que se deu o envio da embaixada capitaneada por Manoel Alves Lima. Em seguida, trato da primeira fase da missão do tenente-coronel, convertido em embaixador, quando se encontrava retido na Bahia, transformando-se num observador privilegiado da guerra de independência (1822-1823) travada naquela província. Por fim, na terceira e última parte deste artigo, centro as atenções na recepção e no tratamento que o embaixador de Onim recebeu do imperador e das demais autoridades do Rio de Janeiro.

\section{Um histórico das relações Onim-Brasil}

Antes do envio da embaixada sob a responsabilidade de Manoel Alves Lima, os reis do Onim já haviam remetido ao Brasil outras duas missões diplomáticas, a primeira em 1770 e a segunda em 1807, ambas com o objetivo de discutir os termos do comércio de 
escravos realizado entre aquele porto e o de Salvador. A prática da qual os monarcas de Onim lançavam mão não era uma novidade para as autoridades luso-brasileiras, muito menos para os demais soberanos do Golfo do Benim. Vale recordar, nesse sentido, que, entre 1750 e 1818, a capital baiana recebeu outras cinco embaixadas vindas do Daomé ${ }^{2}$ e, ainda, uma representação especial mandada pelo rei de Ardra (Porto Novo).

No início da segunda metade do século XVIII, o Onim era governado por Akinshemoyin, cujo reinado (c. 1760-1777) foi marcado pela abertura da região ao tráfico transatlântico de escravos. Segundo a tradição oral corrente naquela região, resgatada por Robert S. Smith e Kristin Mann, o fato resultou de um convite que o citado monarca fizera a um grupo de negociantes luso-brasileiros, que ele conheceu quando esteve exilado em Apa, durante o reinado de seu irmão e predecessor, o rei Gabaro, para que aqueles transferissem seus negócios para o reino de Onim (SMITH, 1978, p. 9; MANN, 2007, p. 36). Os negociantes em questão eram liderados por um africano liberto chamado João de Oliveira.

Transportado ainda criança como escravo da África Ocidental para a América Portuguesa, mais precisamente para Pernambuco, Oliveira regressou ao Golfo do Benim em 1733, já adulto e revestido, por seu senhor no Brasil, de poderes para negociar em seu nome a compra de novos cativos. Porém, mesmo depois de alforriado, Oliveira manteve os vínculos comerciais e "afetivos" com o antigo senhor. Como deduziu Costa e Silva: "As relações entre ambos deviam ser, por sinal, especiais, pois, quando o ex-amo faleceu e sua viúva se viu necessitada, Oliveira passou a enviar-lhe socorro regularmente e com liberalidade” (SILVA, 2004, p. 35). Aliás, a relação de Oliveira com a terra natal de seus outrora senhores também parecia ser bastante peculiar, posto que, como ainda dão conta os relatos orais repassados de geração em geração naquela costa da África, ele não só destinou vultosas esmolas - muitas delas em escravos - para as obras de diversas ordens religiosas no lado de cá do Atlântico, como escolheu morrer e ser enterrado no Brasil, à moda do cerimonial religioso católico. Quer dizer, com todos os sacramentos e encomendas de orações póstumas a que tinha direito para a "salvação de sua alma" (SILVA, 2004, p. 36). Com efeito, aos 
setenta anos de idade, após trinta e sete anos de dedicação exclusiva ao tráfico de escravos realizado no Golfo do Benim, Oliveira resolveu se retirar definitivamente para a Bahia, em 1770, quando de lá saiu a bordo da embarcação Nossa Senhora da conceição e Almas (VERGER, 1987, p. 264), na companhia de nada mais nada menos que quatro cabeceiras (emissários) de Akinshemoyin.

Embora não seja possível afiançar com absoluta certeza, é presumível que Oliveira e Akinshemoyin estivessem mancomunados uma derradeira vez em prol do tráfico de escravos a partir do porto de Onim. Nesse sentido, é preciso recordar que a ascensão do comércio negreiro do Onim coincidiu com o acentuado declínio do fluxo de exportação de escravos de Ajudá (Ouidah), porto controlado desde 1727 pelo Daomé, o que, por sua vez, minou a política dos reis daomeanos de procurar obter para si o exclusivismo das transações comerciais com os estrangeiros acostumados a negociar naquela região da África (LAW, 1983). Diante desse quadro, não surpreende que, já por volta do final da década de 60 do Setecentos, o Onim tivesse se convertido em um reino concorrente e, sobretudo, inimigo do Daomé, fato que certamente não passou despercebido a Oliveira, principal armador daquele porto, nem por Akinshemoyin, cuja soberania estava diretamente atrelada à continuidade do comércio negreiro na costa abaixo de sua jurisdição. Estando ambos interessados em retirar o tráfico de Onim do controle do Daomé, é possível pensar que Akinshemoyin tenha mandado seus emissários ao encalço de Oliveira que, sendo bem relacionado com os comerciantes da Bahia, não teria dificuldades em introduzi-los no cenário público e político da capital baiana. A partir dessa suposição, é plausível cogitar ainda que a missão daqueles quatro indivíduos era conquistar não só a confiança dos comerciantes da praça de Salvador, mas possivelmente também angariar a simpatia das autoridades governativas da América Portuguesa e, por via de regra, das do próprio Portugal, para manutenção da dignidade e da independência do comércio negreiro de Onim em relação às pretensões daomeanas.

Porém, a sorte não acompanhou os viajantes da embarcação Nossa Senhora da conceição e Almas. Logo que aportou em Salvador, o navio foi apreendido sob a suspeita de transportar artigos 
contrabandeados. Oliveira e os quatro emissários de Akinshemoyin, tomados erroneamente como parte da carga de setenta e cinco escravos trazida na ocasião, também foram detidos para investigação. Passado mais de um mês desse incidente, Oliveira, com a ajuda de um "[...] atestado dos comerciantes da Bahia, no qual eram confirmados os [seus] serviços prestados [...] ao comércio da Costa da Mina" (VERGER, 1987, p. 211) conseguiu provar sua inocência e resgatar todos os seus bens, o que, por conseguinte, implicou a liberação dos cabeceiras do rei de Onim. No entanto, tão logo liberados os emissários de Akinshemoyin, também foram obrigados "[...] a retornar para junto do mesmo rei” (VERGER, 1987, p. 264), frustrando qualquer expectativa que o monarca de Onim e Oliveira pudessem alimentar em relação àquela missão, aparentemente desprovida de maiores ambições.

Caráter bem diferente teve a embaixada enviada ao Brasil no início do século XIX pelo príncipe Ajan, o mesmo que, alguns anos depois, nomeou Manoel Alves Lima seu representante junto a D. Pedro I. O primeiro embaixador de Ajan no Brasil chegou a Salvador a 1 de outubro de 1807, e foi recebido pelo conde da Ponte, governador da Bahia, onze dias mais tarde, após a conclusão das providências protocolares de praxe das relações afro-luso-brasileiras. Questionado pelo governador acerca do objetivo de sua missão, o representante de Onim se limitou a informar que havia sido incumbido por seu soberano de entregar uma carta ao príncipe regente de Portugal, D. João, devendo, portanto, seguir viagem ao seu encontro. Mal sabia ele que, em pouquíssimos dias, D. João e sua corte deixariam Lisboa em direção ao Rio de Janeiro, fugindo do cerco das tropas de Napoleão, e que, por essa razão, dentro de mais alguns meses, aportariam por um brevíssimo tempo em Salvador. De qualquer modo, para azar do embaixador, desde 1805, o conde da Ponte estava instruído a reter na Bahia toda comitiva africana, enquanto as correspondências que elas portassem não fossem encaminhadas à corte, a qual, depois de examinar o conteúdo e pesar as vantagens e desvantagens em receber os seus respectivos emissários, decidiria pela permissão ou não da viagem dos mesmos até Lisboa. Com isso, as autoridades lisboetas pretendiam, dentre outras coisas, evitar os elevados gastos que a recepção daquelas embaixadas 
custava ao Erário Régio. Confrontado, destarte, pelo governador da Bahia, o embaixador de Onim demonstrou a sua insatisfação e se recusou a entregar ao conde da Ponte a carta que Ajan escrevera para D. João, episódio que serviu de pretexto para o governador negar-lhe, inclusive, a permanência em Salvador, despachando-o de volta para a África Ocidental no primeiro navio para o Onim (VERGER, 1987, p. 278-279).

Entretanto, a relutância do embaixador em entregar a carta de Ajan ao governador não impediu o conde da Ponte, provavelmente informado pelo capitão da embarcação que transportara o supracitado encarregado até a Bahia, de conhecer o seu conteúdo e de remetê-la, acompanhada de uma análise sua, ao visconde de Anadia, a quem era subordinado. É, pois, através do relato do conde da Ponte, no qual ele atualiza o visconde de Anadia sobre a delicada situação da política interna vivenciada no Onim na primeira década do Oitocentos, que as ambições da embaixada enviada por Ajan são denunciadas. Segundo a tradição oral, Ajan teria sido escolhido como rei, entre 1800 ou 1805, pelo conselho de anciões de Onim, após a morte de seu pai, Kutere (que sucedeu a Akinshemoyin). Todavia, no momento em que a embaixada de Ajan chegou à Bahia, a sua autoridade real ainda não havia sido oficialmente reconhecida pelo obá do Benim, de quem os reis de Onim eram vassalos. Esse reconhecimento dependia de uma antiga formalidade, na qual os restos mortais do rei anterior deviam ser levados à presença do monarca do Benim que, então, reconhecia o novo rei eleito pelos anciões. Ocorre que o irmão mais velho de Ajan, Osinlokun (ou Esinlokun), e seus partidários estabeleceram uma forte oposição a seu governo, impedindo-o de realizar tal solenidade (LAW, 1968, p. 46-54), o que, como era de se esperar, deixou Ajan numa posição desconfortável. Isso posto, é de se suspeitar que a missão diplomática enviada em 1807 por Ajan tivesse por principal desígnio atrair o apoio político de Portugal e, sobretudo, o respaldo econômico e militar dos mercadores do Brasil, notadamente os da Bahia, para fazer frente à oposição de Osinlokun. ${ }^{3}$ Tal percepção parece não ter escapado à compreensão do conde da Ponte, que, em comunicação dirigida ao visconde de Anadia, datada de 14 de outubro de 1807, frisou ao Secretário de Estado que o objetivo daquela primeira embaixada enviada por 
Ajan era "[...] em nada relativo ao comércio daqueles portos, e em tudo dispendioso à Real Fazenda" (VERGER, 1987, p. 277), o que a tornava, na sua concepção, insignificante, quer para os interesses de Portugal na América, quer para as suas pretensões na África.

O fracasso da missão não desencorajou Ajan do propósito de selar e, acima de tudo, exibir uma relação próxima e especial com o príncipe regente de Portugal. Contudo, o reinado de Ajan coincidiu com o advento da política internacional antiescravista da Grã-Bretanha, que, após a abolição do tráfico de escravos realizado por mercadores britânicos em 1807, passou a pressionar a coroa portuguesa para que suprimisse o tráfico realizado por seus súditos, em especial os residentes da América Portuguesa. As pressões britânicas se intensificaram depois de 1808, quando a Casa de Bragança, foi obrigada a recorrer à assistência da Royal Navy da Inglaterra para se transferir até o Rio de Janeiro e escarpar das pretensões expansionistas de Napoleão na Europa. Na ocasião, como forma de compensação, o governo britânico impôs ao congênere português uma série de acordos, entre os quais estão os tratados de 1810 e de 1815, que legislavam concomitantemente a limitação do comércio luso-brasileiro de escravos às possessões da coroa portuguesa na África e América, e a plena proibição desse comércio acima da linha do Equador. Como é de se imaginar, essas medidas tiveram um grande impacto negativo no comércio negreiro realizado na costa da África Ocidental ao longo da segunda década do século XIX, que não passou despercebido pelas autoridades africanas.

Em 1810 e 1811, os reis de Ardra e do Daomé enviaram ao Brasil suas embaixadas para tentar negociar com D. João a continuidade do tráfico luso-brasileiro de escravos em seus respectivos portos (VERGER, 1987, p. 279-283; ARAÚJO, 2011, p. 9-12). Segundo uma informação que nos chega por meio de Jaime Rodrigues (2008), o rei de Onim também não se manteve indiferente à nova conjuntura do tráfico transatlântico de escravos da África Ocidental criada pela política externa da Grã-Bretanha e, em março de 1812, remeteu uma "Carta [...] ao rei de Portugal, franqueando aos portugueses [e vale acrescentar, aos brasileiros] portos em seus domínios" ${ }^{4}$, e protestando contra a sua exclusão, assim como a dos demais soberanos da África, das discussões em relação ao futuro do comércio negreiro. 
Seja como for, apesar dos esforços coligados daqueles monarcas africanos, o governo Joanino, então submetido às aspirações britânicas, não lhes deu ouvidos, e os embaixadores de Ardra e do Daomé regressaram sem sucesso para junto dos seus soberanos em 1812. Quanto à carta do rei de Onim, e até onde se sabe, também não obteve resposta do governo Joanino. A partir de então, as relações afro-luso-brasileiras quedaram num silêncio que só foi rompido em 1818, quando o rei Guezo, do Daomé, enviou uma nova embaixada ao Brasil, que redundou, no entanto, numa tentativa frustrada (ARAÚJO, 2011, p. 13-14). Somente no início da década seguinte, já em meio ao processo de independência do Brasil, as relações afro-luso-brasileiras foram reativadas. Curiosamente, não por uma embaixada do Daomé, reino com maior passado e tradição nas negociações "de Estado para Estado", mas pela segunda embaixada enviada ao Brasil por Ajan, e entregue aos cuidados do tenente-coronel Manoel Alves Lima.

\section{A passagem do embaixador Manoel Alves Lima pela Bahia}

Sabe-se muito pouco sobre a vida e a origem de Manoel Alves Lima. Ao confrontar os registros de passaportes conservados no Arquivo Público do Estado da Bahia com os papéis sobre o combate ao tráfico transatlântico de escravos arquivados no Public Record Office, Verger deduziu, com boa margem de segurança, tratar-se de um proeminente negociante de escravos do circuito entre a Bahia e o Golfo do Benim.

A conclusão de Verger se deve, em parte, ao fato de Manoel Alves Lima aparentar transitar com certa regularidade entre uma margem e outra do Atlântico, "[...] indo em grande aparato para a costa da África, seguido cada vez de cinco dos seus criados, nos dias 3 de setembro de 1829 e 22 de janeiro de 1830" (VERGER, 1987, p. 283-284).

No entanto, são as companhias de Manoel Alves Lima nas suas travessias que dão sustentação à hipótese levantada por Verger. Segundo ele: "Em uma das suas voltas à Bahia em 20 de novembro 
de 1827, vindo do Onim em 43 dias”, Manoel Alves Lima viajou "[...] a bordo do brique [sic] brasileiro Camboata, cujo capitão era José Joaquim da Costa Freitas [...] em companhia dos capitães e mestres dos [também] navios brasileiros Providência, Diana, Henriqueta e Dois Amigos" (VERGER, 1987, p. 284). É digno de nota o fato de que essas quatro embarcações terem sido apreendidas pelos cruzadores da Royal Navy, em alguma parte da costa da África, sob a suspeita ou o crime flagrante de participação no tráfico ilegal de africanos para o Brasil.

Aceitando que Verger esteja correto na identificação da ocupação de Manoel Alves Lima e do espaço geográfico onde ele atuava, é de se imaginar que o negociante de escravos tenha estado na Bahia inúmeras vezes antes de ser nomeado embaixador do rei de Onim. Contudo, se é possível conjecturar que as razões que o levaram anteriormente a Salvador eram de caráter comercial, agora, na qualidade de encarregado do rei Ajan, é de se suspeitar que ele não tenha desembarcado em Salvador simplesmente pelo fato de aquele porto lhe ser familiar, mas sim porque tenha sido instruído a seguir um procedimento comum das práticas diplomáticas que regiam as relações afro-luso-brasileiras.

Nesse sentido, importa observar que, desde a chegada da primeira delegação da África Ocidental, em 1750, Salvador foi a porta de acesso utilizada por todos os embaixadores africanos que partiam em direção à corte Bragantina. Lá, eles eram recebidos com toda a pompa e circunstância condizente a seu status político e diplomático. A princípio, cabia aos vice-reis do Estado do Brasil fazerem as honras da casa. Depois, com a transferência da capital da colônia para o Rio de Janeiro, em 1763, essa incumbência passou aos governadores da capitânia da Bahia. As recepções, lembra Silvia Lara (2007, p. 194-202), eram verdadeiros espetáculos e, ainda que os festejos não se destinassem tão somente a saudar os ilustres visitantes, já que eram entrecruzados com as celebrações das datas de júbilo e congraçamento da família real portuguesa, eles contavam com desfile dos regimentos da infantaria, salvas de canhões, cortejos da nobreza da terra em trajes de gala, além da tradicional troca de cartas e presentes entre as autoridades africanas e metropolitanas. Ademais, é preciso levar em conta que, desde o início do século XIX, Salvador havia 
se convertido numa espécie de antecâmara, onde os embaixadores africanos deviam aguardar o salvo-conduto ou, em outras palavras, a liberação para seguirem viagem e se apresentarem à corte dos Bragança, estivesse ela instalada em Lisboa ou no Rio de Janeiro.

No momento em que o embaixador Manoel Alves Lima chegou à Bahia (acredita-se que em meados de 1822), não havia, no entanto, a mínima condição de ordem cívica e política, tanto na capital quanto no Recôncavo Baiano, para a realização dos procedimentos tradicionalmente adotados na recepção dos embaixadores africanos. Essa, pelo menos, é a impressão que deixam transparecer as duas cartas - quiçá, as primeiras - endereçadas pelo dito embaixador a D. Pedro, e publicadas por Costa e Silva (2005), quando aquele ainda atendia pelo título de Príncipe Regente do Brasil e, por conseguinte, pelo tratamento de Vossa Alteza Real.

Numa delas, escrita provavelmente na segunda quinzena de junho de 1822, o embaixador relata ao príncipe regente os atritos ocorridos entre os representantes do governo civil da Bahia e o comandante militar da província, o Governador de Armas Ignácio Luiz Madeira de Melo. Conforme narrado por Manoel Alves Lima, tendo a Câmara e a Junta local escolhido o dia 12 de junho para aclamar D. Pedro como Defensor Perpétuo e Constitucional do Brasil, tal qual ocorrera há exatamente um mês no Rio de Janeiro, o Governador de Armas deu ordens para que suas tropas cercassem a Praça Municipal (hoje Praça Tomé de Sousa) e fizessem “[...] prender a Câmara ou assassiná-la, e da mesma sorte a Junta Provisória” no caso de ousarem reconhecer a autoridade do príncipe regente (SILVA, 2005, p. 197-198). Na carta seguinte, redigida provavelmente entre fins de agosto e princípios de setembro de 1822, o embaixador dá conta do acirramento dos embates por toda Bahia entre brasileiros natos e portugueses residentes.

Alguns dos eventos descritos nessa segunda carta são bem conhecidos, como é o caso do fechamento do jornal O Constitucional, periódico de tendência pró-independentista, e das agressões sofridas por seu redator, Francisco Gê Acaiaba de Montezuma. Já outros episódios são menos célebres, porém, não menos elucidativos da tensão e da animosidade que tomara conta do espaço de convivência e de debate público de Salvador e de outros centros urbanos do 
país naquele período, a exemplo dos xingamentos disparados desde as tribunas de um teatro da capital baiana por um grupo de caixeiros portugueses contra a pessoa de D. Pedro (SILVA, 2005, p. 198-200).

Outras cartas foram enviadas da Bahia por Manoel Alves Lima para D. Pedro. Verger descobriu na Biblioteca Nacional do Rio de Janeiro uma série de correspondências, todas datadas do primeiro semestre de 1823, contendo informações relativas à posição, aos avanços e recuos e ao estado das tropas portuguesas e brasileiras no teatro de guerra que se transformou a Bahia. Talvez Manoel Alves Lima as tenha escrito por força do hábito militar; afinal, não nos esqueçamos de que antes de ser embaixador e - é quase certo - negociante de escravos, ele era também um tenente-coronel. Vale notar, aliás, que o teor das cartas mencionadas por Verger ainda não recebeu o devido tratamento, seja pela historiografia dedicada à crise do Antigo Regime na América Portuguesa, seja pela historiografia centrada nas especificidades da Independência.

Por ora, contudo, e para os interesses deste artigo, importa ajuizar algumas linhas sobre a pretensão que o embaixador do Onim pode ter acalentado com o envio dessas cartas ao imperador do Brasil, ao longo da guerra pela independência travada em solo baiano. Como já foi antecipado alguns parágrafos atrás, desde o início do século XIX as formalidades que regiam a recepção dos embaixadores africanos na Bahia previam a sua retenção em Salvador, "[...] com toda a atenção que pode merecer seu caráter” (VERGER, 1987, p. 280), até que a corte, de posse das cartas que eles traziam, autorizasse a realização da segunda parte da sua viagem. No entanto, era de conhecimento da população e dos negociantes de escravos de Salvador que, desde a realocação da corte Bragantina para o Rio de Janeiro, nenhuma das quatro embaixadas vindas da África Ocidental que ali aportou a partir da aludida data foi autorizada a seguir viagem.

Questões a princípio de ordem doméstica e, em seguida, de ordem internacional (aqui já mencionadas) concorreram para esse panorama negativo das relações afro-luso-brasileiras nas duas primeiras décadas do Oitocentos. Diante disso, a hipótese que me parece mais provável é que Manoel Alves Lima tenha buscado, por meio dos meticulosos relatórios sobre os eventos ocorridos no embate direto entre as forças brasileiras e lusitanas na Bahia, permeados por um 
tom explicitamente laudatório a D. Pedro e seu governo, ganhar a confiança do imperador na esperança de que isso, de algum modo, servisse-lhe para abrir o caminho até o Rio de Janeiro. Destarte, as cartas assinadas por Manoel Alves Lima e encaminhadas à corte carioca entre 1822 e 1823 estavam longe de constituir "[...] obra de um louco, atacado de um delírio de grandeza, escrevendo ao imperador do Brasil [...] usando o título de embaixador do rei de Onim e tomando-se por tenente-coronel” (VERGER, 1987, p. 283). Pelo contrário, elas devem ser lidas como uma estratégia diplomática utilizada para atingir o objetivo da sua missão.

E qual era, afinal, esse objetivo? Embora saibamos de antemão que a incumbência final de Manoel Alves Lima era transmitir a D. Pedro I o reconhecimento do Império, uma questão de interesse de Ajan e outros reis da África Ocidental, as cartas reveladas originalmente por Verger e depois por Costa e Silva não fazem menção, nem mesmo de forma implícita, a esse desígnio (REVISTA DO IHGB, 1981, p. 162). Ciente dessa ausência, Costa e Silva elaborou uma tese que nos parece bastante plausível:

Como não se passava semana sem chegar a Salvador mais de um barco de Lagos [leia-se Onim] e o próprio Alves de Lima [sic] viajasse constantemente, ao que tudo indica, entre as duas cidades, teria havido tempo para que o ologun [rei] mudasse o sentido de sua embaixada [...] ao receber notícias do que se passava no Brasil (SILVA, 2005, p. 203).

Acolhendo, assim, a tese apresentada por Costa e Silva é lícito conjecturar que o reconhecimento da independência do Brasil não constituía, de fato, finalidade original da tarefa encarregada pelo rei de Onim a Manoel Alves Lima. E é compreensível que não o fosse. Sendo a Bahia o principal destino dos navios negreiros carregados em Onim, não convinha a Ajan correr o risco de tomar partido na querela luso-brasileira enquanto não ficasse decidido qual dos dois Bragança, D. João VI ou D. Pedro I, controlaria o porto de Salvador.

Não obstante, a data aproximada da chegada do embaixador à capital baiana indica que ele tenha sido nomeado logo no princípio de 1822. Nesse período, recorda Lúcia M. Bastos P. Neves (2009), ainda 
que a ideia de independência já tivesse se manifestado em alguns círculos políticos e até sido veiculada em certo número de periódicos e panfletos, a decisão pela separação do Brasil de Portugal ainda não havia sido tomada. Portanto, seguindo essa linha de raciocínio, pode-se sugerir que a intenção primordial da terceira embaixada do Onim no Brasil fosse cumprimentar D. Pedro, elevado à condição de Príncipe Regente do Reino do Brasil após o regresso de seu pai para Portugal em 1821, na esperança de reatar os laços de amizade e de comércio entre o Onim e o Brasil, abalados desde o esfriamento das relações afro-luso-brasileiras, no final da primeira década do século XIX, em face da oposição que lhe movera a Grã-Bretanha. Não é de se estranhar, assim, que as cartas remetidas da Bahia por Manoel Alves Lima tenham, ao que parece, despertado pouco interesse nas autoridades do Rio de Janeiro, envoltas, desde o segundo semestre de 1822, na campanha pelo reconhecimento do Império.

O embaixador do Onim deve ter se apercebido disso, pois, em sua carta de $1^{\circ}$ de abril de 1823 , queixou-se: "Falei em particular com Sua Majestade Fidelíssima, Pai de V.M.I. [Vossa Majestade Imperial]. Ele me determinou que eu fosse a V.M.I.; aqui [...]”, no entanto, "[...] me acho retido sem poder sair" (VERGER, 1987, p. 283). Ao que conclui: "Esta província atualmente se acha inabitável, e não dão licença para a minha retirada” (Ibid., loc. cit.).

Ainda não foram localizados documentos que comprovem a procedência dessa conversa entre Manoel Alves Lima e D. João VI. Ainda assim, não descartamos a ideia de que Manoel Alves Lima tenha alegado trazer notícias confiadas pelo pai de D. Pedro em pessoa, na expectativa de que lhe garantissem o direito de passagem até o Rio de Janeiro e, obviamente, uma audiência com o imperador brasileiro. Todavia, o preço da simpatia da corte carioca àquela época era elevado. Com efeito, um episódio sucedido algum tempo depois da expulsão das tropas portuguesas da Bahia sinaliza com perfeição qual era a condição sine qua non para ser recebido - e bem! - na corte de D. Pedro I durante os primeiros anos de seu reinado. Refiro-me ao fracasso da missão do conde de Rio Maior, enviada por D. João VI, para negociar uma reconciliação do Brasil com Portugal. Chegada ao Rio de Janeiro, a 18 setembro de 1823, a missão de Rio Maior foi friamente recebida e intimada, poucos 
dias depois, a se retirar do país após seus encarregados alegarem não estar autorizados a reconhecer a independência plena do Império (CERVO; MAGALHÃES, 2000, p. 104-107).

Diante do ocorrido, não é impossível cogitar que, uma vez inteirado dos detalhes do malogro da missão reconciliatória orquestrada pelo governo Joanino, Manoel Alves Lima tenha se retirado novamente para o Onim, onde, após ter exposto a Ajan os acontecimentos sucedidos na Bahia e no Rio de Janeiro, retornou ao Brasil revestido de plenos poderes a ele conferidos por este e outros soberanos para dar cabo de sua tarefa. Infelizmente, a falta de documentos nos impede de afirmar com segurança se essa hipótese procede. Independente disso, os rastros e vestígios deixados pela missão de Manoel Alves Lima quando de sua passagem pela Bahia, sugerem que estamos ao menos próximos da compreensão dos caminhos que levaram o embaixador do Onim até o Rio de Janeiro.

\section{A recepção do embaixador Manoel Alves Lima no Rio de Janeiro}

José Vieira Fazenda, memorialista carioca que vivenciou a passagem do Oitocentos para o Novecentos, deixou registrado em suas Antiqualhas e memórias do Rio de Janeiro que a embaixada chefiada por Manoel Alves Lima foi recebida na corte de D. Pedro I em 1824. Sem esconder certo tom de ironia, J. V. Fazenda sugere que "a aliança dos régulos africanos" à causa emancipacionista encabeçada pelo governo do Rio de Janeiro "já era para o Brasil [motivo de] grande felicidade", posto que, até aquele momento, "nas cortes europeias o reconhecimento da nossa emancipação [ainda] promovia tramoias e tricas políticas" (REVISTA DO IHGB, 1927, p. 473). Dessa feita, foram os monarcas da África os primeiros de semelhante estirpe a reconhecerem a coroa de D. Pedro I.

É fato conhecido, no entanto, que nem a recepção do embaixador nem a declaração de reconhecimento por parte dos reis africanos chegaram a ser incluídas no Archivo Diplomatico da Independência organizado pelo próprio Ministério das Relações Exteriores do Brasil para as comemorações do primeiro Centenário da Independência, 
em 1922. Segundo Costa e Silva, essa exclusão evidencia a pouca importância que a sobredita missão teve para os políticos e burocratas do Primeiro Reinado - e, convenhamos, para os congêneres da República Velha que participaram da organização do referido Archivo -, para quem Manoel Alves Lima "[...] representava chefes de povos negros, sem presença e sem voz no que se chamava concerto, ou desconcerto, das nações” (SILVA, 2005, p. 204).

Não surpreende, assim, que os registros sobre a tramitação do embaixador do Onim pela corte do Rio de Janeiro tenham se perdido na memória e na massa documental do Arquivo Histórico do Itamaraty, responsável pela guarda dos papéis da antiga Secretaria de Estado dos Negócios Estrangeiros. Sem embargo, a indicação da existência dos documentos agrupados na Pasta 06, sob o título de Missões Especiais Estrangeiras Diversas, é recente. O mérito de sua revelação se deve à Mariza de Carvalho Soares (2014) que, em artigo acerca do papel simbólico e político das cartas e presentes trocados entre os monarcas portugueses e africanos, topou com a dita documentação. No entanto, apesar de mencionar os papéis, a autora não os toma como objeto central de estudo, posto que sua preocupação insidia sobre outro aspecto das relações afro-luso-brasileiras. Dessa forma, o seu conteúdo e análise ainda se fazem inéditos.

Manoel Alves Lima chegou ao Rio de Janeiro a 6 de julho de 1824, a bordo da escuna Mariana, que funcionava como correio entre a Bahia e a corte imperial. Tão logo aportou no porto carioca, o embaixador de Onim correu em notificar sua chegada a João Severiano Maciel da Costa, marques de Queluz, que então ocupava a chefia da pasta dos Negócios do Império (AHI, 273/1/13), cujas atribuições incluíam, entre outras coisas, o controle dos portos e da navegação interna, bem como do cerimonial e etiqueta dos eventos oficiais da corte imperial.

Nota-se, desse modo, que o estado de sítio imposto a Salvador pelas forças portuguesas do Governador de Armas Ignácio Luís Madeira de Melo, entre meados de 1822 e a conclusão do primeiro semestre de 1823, não constituiu em razão exclusiva da longa retenção do embaixador naquela cidade. Fato é que, a despeito dos embaraços que a conjuntura baiana nos primeiros anos da década de 1820 possam ter causado à missão de Manoel Alves 
Lima, o principal empecilho para que ele obtivesse a tão almejada autorização para seguir viagem até o Rio de Janeiro era certamente de ordem internacional.

Visando à obtenção do reconhecimento britânico, o governo imperial procurou, desde o princípio, dar vivas provas de sua estima e consideração pelas relações diretas do Brasil com a Grã-Bretanha, estabelecidas a partir de 1808. Grosso modo, essa postura implicou o gabinete carioca a mostrar-se disposto não apenas em respeitar os acordos políticos e comerciais assinados na década anterior pelo governo Joanino, como também em renová-los e até ampliá-los, mediante novas negociações, em favor dos interesses expressados pelo gabinete londrino (BETHELL, 2002, p. 67-68). Nesse sentido, o prolongamento da estadia de Manoel Alves Lima em Salvador, sobretudo depois da expulsão das tropas portuguesas da Bahia no início de julho de 1823 , deve ser compreendido à luz do enquadramento anglo-brasileiro.

Convém lembrar que os ministros de $\mathrm{D}$. Pedro I não ignoravam que os interesses da Grã-Bretanha gravitavam em torno da extinção do tráfico transatlântico de escravos e, embora não estivessem verdadeiramente dispostos a empreender negociações para a sua supressão, não convinha dar ao gabinete londrino mostras de sua relutância em fazê-lo, posto que isso pudesse atrasar ainda mais a concessão do reconhecimento britânico. Desse modo, a recepção oficial de um embaixador com envolvimento direto no comércio negreiro, que representava, ademais, um dos principais reinos exportadores de escravos da África Ocidental, era algo a ser evitado. Daí a razão para os estadistas do Primeiro Reinado, em especial aqueles que compuseram o primeiro gabinete de D. Pedro I, sob a liderança de José Bonifácio de Andrada e Silva, conhecido por sua postura pró-abolicionista, terem optado, ao menos inicialmente, em dar à embaixada de Onim tratamento semelhante ao dispensado pelas autoridades Joaninas às embaixadas de Ardra e do Daomé chegadas ao Brasil no início da segunda década do século XIX.

Entretanto, em 1824, as negociações com a Grã-Bretanha andavam em marcha lenta e, para o aborrecimento dos representantes do Brasil em Londres, enquanto o Foreign Office mostrava-se relutante em reconhecer o Império brasileiro, cada vez mais próximo ficava 
de um entendimento naquele sentido com os representantes das Repúblicas hispano-americanas ali credenciados (CALÓGERAS, 1998, p. 211). Portanto, é provável que essa falta de deferência pelo gabinete londrino à causa brasileira tenha desagradado o gabinete carioca que, talvez numa demonstração de altivez, decidiu receber o embaixador de Onim no Rio de Janeiro. Entrementes, se no âmbito internacional os estadistas da Grã-Bretanha eram aqueles que deveriam ser agraciados, no âmbito doméstico o governo imperial não podia privar a elite mercantil e fundiária de menor consideração, até porque era ela que lhe dava sustentabilidade. Assim sendo, não se pode descartar que, como defende Costa e Silva, a "razão para a boa acolhida" da embaixada de Onim na corte imperial tenha tido o significado de tranquilizar "[...] os mercadores de gente, inquietos ante a possibilidade de que, com a separação do Brasil de Portugal, para eles se fechassem [de imediato] os embarcadouros [de escravos na África]" (SILVA, 2005, p. 204).

A recepção da comitiva diplomática do Onim, composta por Manoel Alves Lima, por seu secretário José Vicente de Santa Ana e por seus fâmulos, não lembrou nem de longe a recepção dispensada às delegações daomeanas chegadas a Salvador no decorrer da segunda metade do século XVIII. Como indica o silêncio da documentação acerca do cerimonial seguido na ocasião, a escuna Mariana, que trouxera o embaixador, não foi saudada pela artilharia das fortalezas que circundavam a Baía de Guanabara, tal qual se sucedera em 1751 na entrada da Baia de Todos os Santos da embarcação com os enviados do rei Tegbessu. Da mesma forma, os regimentos de infantaria da corte imperial não desfilaram em trajes de gala e, ao que parece, muito menos em trajes usuais, diante da residência que abrigou o embaixador de Onim no Rio de Janeiro, tal como acontecera mais de meio século antes na frente do Colégio da Companhia de Jesus em Salvador, onde ficaram hospedados os encarregados do monarca daomeano (VERGER, 1987, p. 257-261; LARA, 2001, p. 151-165). Fato é que a discrepância entre os cerimoniais de "boas vindas" diplomáticas encenados na Salvador Setecentista e no Rio de Janeiro Oitocentista tinha sua razão de ser. Enquanto as recepções às embaixadas africanas realizadas na cidade baiana foram moldadas à forma e ao estilo do Antigo Regime, caracterizado 
pela grandiosidade, ostentação e suntuosidade dos eventos públicos (LARA, 2007, p. 173-218), a recepção à embaixada de Onim na cidade carioca parece ter seguido o protocolo e a etiqueta de admissão de agentes diplomáticos da era pós-napoleônica, pautado num caráter mais austero, porém, não menos digno. No mais, importa assinalar que Manoel Alves Lima foi recebido na corte de D. Pedro I com todas as devidas e merecidas honras exigidas pela sua condição diplomática.

O embaixador foi recebido pelo imperador em pessoa no dia 20 de julho de 1824, no Paço Imperial da Boa Vista (AHI, 273/1/13). Uma vez que durante o Brasil Joanino e, posteriormente, no Brasil Imperial, o Paço do Rio de Janeiro servia de sede administrativa da corte, sendo usado pelos três dirigentes da família dos Bragança como local de despacho e de recepções públicas, à medida que o Paço da Boa Vista servia de residência oficial e para recepções de caráter íntimo e reservado dos monarcas brasileiros (SCWARCZ, 1998, p. 208-219), é de se crer que Manoel Alves Lima tenha tido uma audiência privada com D. Pedro I nesse dia. Honraria delegada a poucos, mesmo em se tratando de representes estrangeiros.

Como era habitual do cerimonial de recepção diplomática seguido na corte brasileira, herdado da portuguesa, a primeira audiência tinha como objetivo apresentar formalmente as duas partes através da entrega da credencial do enviado estrangeiro ao imperador. Era, portanto, um procedimento indispensável à validação do caráter e das atribuições reclamadas pelo diplomata estrangeiro chegado ao Rio de Janeiro. Dito isso, não resta dúvidas que o título de embaixador de Onim reivindicado por Manoel Alves Lima foi aceito e reconhecido por D. Pedro I, a quem este presenteou, na ocasião, com uma bengala, ${ }^{5}$ objeto que, segundo os costumes das relações interestatais mantidas pelos reinos africanos, tinha valor simbólico equivalente ao das cartas patentes utilizadas pelos monarcas europeus para certificar a autoridade de seus respectivos representantes diplomáticos.

Oficialmente apresentado, o embaixador tratou de transmitir ao imperador os cumprimentos em nome do obá do Benim, do rei Ajan do Onim e dos demais reis africanos a quem havia sido encarregado de representar, "[...] por sua autoridade constituída pelo 
Governo da Província da Bahia” (AHI, 273/1/13). Esse fato serve como forte indício de comprovação da suspeita de que os monarcas africanos estavam inteiramente a par dos eventos ocorridos do lado de cá do Atlântico e só optaram em definitivo pelo recolhimento da independência do Brasil depois que a autoridade imperial de D. Pedro foi efetivamente proclamada na Bahia - onde, vale recordar, absorvia-se a maior parte dos escravos embarcados a partir da costa da África Ocidental.

Mas voltemos à audiência concedida por D. Pedro I a Manoel Alves Lima. Junto à declaração de reconhecimento, o embaixador repassou ao imperador uma lista de encomendas de Ajan, ao que parece em sinal de retribuição àquele ato. Constava da lista um baú de tampa curvada e ricamente enfeitado de três palmos de comprimento, por dois palmos de largura e de altura respectivamente. $\mathrm{O}$ interior do baú deveria ser preenchido por seis peças de damasco, isto é, por tecidos de seda com desenhos em forma de ramos de ouro e o seu espaço sobressalente deveria ser ocupado por grandes corais, peça de adorno muito valiosa na cultura africana. Ajan desejava ainda uma carruagem grande e em bom estado de uso; dois pares completos de artilharia calibre três; quatro elegantes chapéus de aba larga e arredondados, sendo dois deles pretos e dois brancos; e uma bala de canhão, a maior que D. Pedro I conseguisse lhe enviar (AHI, 273/1/13).

À primeira vista, a lista de presentes dirigida por Ajan a D. Pedro I pode parecer inusitada e até incomum para uma relação entre monarcas; no entanto, como exposto por Soares (2014, p. 248-251), a longínqua relação de amizade e reciprocidade nutrida entre os chefes das casas reais africanas e os soberanos das três últimas gerações do século XVIII da Casa de Bragança era marcada pelo volume e pela constância das trocas de presentes de ambas as partes.

Não se sabe se o imperador satisfez as demandas pleiteadas pelo rei de Onim - "No caso afirmativo deu provas de fino diplomata" (FAZENDA, 1927, p. 473). De qualquer maneira, com base na documentação de que dispomos, pode-se afirmar que ao menos o embaixador recebeu o mais respeitoso tratamento do imperador e dos demais estadistas do Primeiro Reinado. 
Talvez, umas das principais evidências disso seja a pensão diária que D. Pedro I concedeu a Manoel Alves Lima para "[...] os suprimentos necessários à subsistência e tratamento próprios à [sua] categoria" (AHI, 273/1/13). Prometida na audiência de 20 de julho de 1824, a pensão passou a ser paga seis dias mais tarde por meio de uma ordem imperial dirigida ao Tesouro Público (AHI, 273/1/13). A ordem estipulava, a princípio, o valor de dezesseis tostões diários, aproximadamente $1 \$ 280$ (mil duzentos e oitenta réis); ${ }^{6}$ porém, por alguma razão que nos é desconhecida, a pensão sofreu um nítido reajuste para cima, sendo pagos à embaixada de Onim $1 \$ 600$ (mil e seiscentos réis) diários. A pensão foi descontada até 17 de agosto de 1824, quando o visconde da Cachoeira, Luís José de Carvalho e Melo, ministro dos Negócios Estrangeiros, notificou ao embaixador a suspenção do seu pagamento (AHI, 273/1/13). Na mesma comunicação, o ministro informou que, havendo o imperador denegado o pedido de uma segunda audiência (ato que, na linguagem diplomática Oitocentista, equivalia à interrupção unilateral do diálogo), ficava o embaixador autorizado a resgatar sua bengala, isto é, a insígnia diplomática que os reis da África Ocidental haviam lhe conferido, e, igualmente, ser liberado para se retirar da corte imperial quando assim o desejasse.

São desconhecidas as razões que levaram o imperador a suspender tanto o pagamento da pensão quanto o diálogo pessoal com o representante de Onim. É provável que a constante escassez de recursos do Tesouro Público o tenha feito repensar o gasto com uma embaixada que pouco somava à principal aspiração internacional pretendida pelo seu governo, ou seja, a obtenção do reconhecimento britânico da independência. Não obstante, é plausível conjecturar que D. Pedro I tenha sido aconselhado por seu Conselho Privativo a distanciar-se da persona do embaixador africano, diante dos malefícios que aquela proximidade pudesse trazer às negociações encetadas com o gabinete londrino. $\mathrm{Na}$ eventualidade de que este tenha sido o caso, vê-se que a recepção e a boa acolhida do embaixador pelo imperador não passaram despercebidas a Henry Chamberlain, cônsul-geral da Grã-Bretanha no Rio de Janeiro àquela época que, em ofício de 29 de janeiro de 1825 para George Canning, deu parte ao 
ministro do Foreign Office sobre suas desconfianças em relação à índole pessoal, ao título e à própria missão de Manoel Alves Lima (KRAAY, 2006, p. 303-304).

Independente de qual tenha sido o motivo, convém destacar que o término da comunicação vis-à-vis entre o embaixador africano e o imperador não implicou no azedume da relação do primeiro com as autoridades imperiais do Rio de Janeiro. Prova disso é que, como também não escapou à percepção de Chamberlain, se por um lado o governo brasileiro retirou-lhe a pensão, por outro, parece ter atendido a outra reivindicação do embaixador, prometendo-lhe uma passagem de regresso à Bahia, bem como para seu secretário e seus criados em algum navio da Marinha Imperial que viesse a içar velas rumo àquele porto situado ao norte do Império (KRAAY, 2006, p. 304).?

Embora a promessa de transporte feita pelo governo brasileiro a Manoel Alves Lima datasse de finais de 1824 e conquanto que a situação financeira do embaixador no Rio de Janeiro já não fosse das melhores naquele tempo, em função da suspensão da pensão anteriormente mencionada e também da falta do ordenado que os monarcas africanos haviam lhe enviado para a sua subsistência pela embarcação Bom Caminho e que fora interceptado por piratas em alto-mar (AHI, 273/1/13), a embaixada de Onim parece ter permanecido em funcionamento durante todo o decorrer de 1825. Com efeito, no momento em que a imperatriz D. Leopoldina deu a luz ao príncipe D. Pedro de Alcântara, na madrugada de 2 de dezembro daquele ano, o embaixador africano integrava o diminuto corpo diplomático estrangeiro que residia, então, na corte carioca. $\mathrm{Na}$ ocasião, ciente da importância daquele acontecimento, e também do seu "dever político", enquanto representante da "pessoa do Imperador de Benim, e dos Seus Reis”, de cumprimentar às Suas Majestades Imperiais pelo nascimento do filho varão, Manoel Alves Lima instruiu José Vicente de Santa Ana a informar-se junto ao ministro dos Negócios Estrangeiros o lugar que ele e seu secretário deveriam ocupar nos atos públicos que tomariam conta da cidade do Rio de Janeiro nos dias seguintes ao nascimento, em especial o da "Solene [e] Imperial festa do Batizado de S.A.I [Sua Alteza Imperial] Recém-nascida” (AHI, 273/1/13). 
Ignoramos se o embaixador tomou mesmo parte nas solenidades preparadas para festejar o nascimento de D. Pedro II. No entanto, em vista do histórico favorável da tramitação burocrática de Manoel Alves Lima na corte carioca apresentado há pouco, é bastante provável que, assim como os reis da África Ocidental foram os primeiros monarcas a reconhecerem a independência do Império, eles também tenham sido uns dos primeiros, ao lado dos reis da Franca e da Grã-Bretanha (únicos monarcas europeus àquele momento com representantes credenciados no Rio de Janeiro), ${ }^{8}$ a congratularem D. Pedro I e D. Leopoldina pelo nascimento do herdeiro presuntivo da coroa brasileira.

\section{Considerações finais}

Como já foi argumentado, os papéis contidos na Pasta 06 são fragmentários e, em face das suas lacunas, não conseguimos aferir informações como o tempo de duração da missão de Manoel Alves Lima. Mas parece ser possível sugerir, com uma relativa margem de certeza, que ela não ultrapassou o ano de 1826, posto que, como já mencionado anteriormente, em 1827 o nome Manoel Alves Lima já figurava entre as identidades de capitães e mestres de navios negreiros detidos pela Royal Navy por participação no tráfico ilícito de escravos entre a costa da África Ocidental e o Brasil (VERGER, 1987, p. 284).

Parece certo, também, que a missão não resultou em nenhum acordo prático, como o de franquear o porto de Onim aos navios brasileiros, o que, em outras palavras, consistiria em converter o Reino de Onim em um protetorado do Império do Brasil, ideia acalentada não só pelo rei de Onim, mas também por outros reis da África Ocidental, já no início da década de 1810, em face das primeiras restrições impostas ao tráfico transatlântico de escravos pelos acordos entre Portugal e Grã-Bretanha. Preocupado com o reconhecimento da independência pelas nações "civilizadas" e interessado em salvaguardar o comércio realizado ao sul do Equador, o governo imperial eximiu-se de qualquer obrigação com os monarcas dos reinos localizados no litoral africano do Atlântico Norte. 
Contudo, parece que, pelo menos em termos simbólicos e morais, o resultado dessa embaixada foi satisfatório. Ao permitir a instalação do embaixador no Rio de Janeiro, socorrê-lo financeiramente, ainda que por tempo limitado, e, até mesmo, permitir a sua participação nos festejos pelo nascimento do futuro imperador, o governo imperial sinalizou aos negociantes de escravos e a seus sócios, parceiros e intermediários na África, que embora não pudesse caminhar na contramão da política internacional avessa à escravidão liderada pela Grã-Bretanha, na política doméstica do país recém-independente pouco ou nada se alterava na medida em que os comerciantes de escravos continuariam a ser requisitados e celebrados na corte imperial. Como de fato ocorreu até pelo menos o final da década de 1840 , conforme deixa transparecer um célebre prognóstico de um ministro dos Negócios Estrangeiros ${ }^{9}$ daquele período sobre a influência então desfrutada por grandes e pequenos traficantes não apenas à mesa dos cidadãos mais ricos e respeitáveis, como também nas cadeiras da Câmara e, como se não bastasse, nos assentos do Conselho de Estado privativo do imperador.

\section{THE LAST EMBASSY OF AN AFRICAN MONARCH IN BRAZIL: MANOEL ALVES LIMA, AN AMBASSADOR OF THE KINGDOM OF ONIM AT THE COURT OF D. PEDRO I}

Abstract: This article focuses on the third embassy of the Kingdom of Onim in Brazil (c. 1822/25). Sent by king Ajan, and headed by Lieutenant Colonel Manoel Alves Lima, this embassy was the last diplomatic mission to an African monarch on Brazilian soil. It was also the only African embassies sent in Nineteenth who obtained permission to complete its purpose, following to Rio de Janeiro to meet the emperor D. Pedro First, who Manoel Alves Lima presented the recognition of the independence of the Empire in the name of Ajan and other sovereigns of "Black Continent". So, from an unprecedented diplomatic documentation, this article seeks thus to reconstruct the history of this embassy in Brazil, and through this understanding the context of AfricanBrazilian historical relations.

Keywords: Diplomacy. Independence. Africa. Brazil. Onim. 


\section{Notas}

${ }^{1}$ Pasta 06 - Missões Especiais estrangeiras diversas: África, Argentina e Bolívia. 1824-1920. Arquivo Histórico do Itamaraty, maço 273/1/13.

${ }^{2}$ São elas as embaixadas dos reis Tegbessu (1750), Agonglô (1795), Adandozan (1805), Agomé (1811), e Gezo (1818) (VERGER, 1987, p. 257-283; ARAÚJO, 2011, p. 1-19). ${ }^{3}$ A disputa entre Ajan e Osinlokun foi longa. Por volta de 1820-1821, Osinlokun usurpou o trono de Ajan, que, por sua vez, refugiou-se em Badagry. Mesmo no exílio Ajan jamais renunciou ao título de rei de Onim e, contando com a preferência do obá do Benim, conseguiu ser reconduzido ao trono de Onim doze ou quatorze anos mais tarde, dando início ao seu segundo reinado, que duraria até a sua morte em 1836 (SMITH, 1978, p. 14-16).

${ }^{4}$ Há aqui uma incongruência entre a tradição oral e a referida fonte documental. A autoria da mencionada carta, guardada na Divisão de Manuscritos da Biblioteca Nacional do Rio de Janeiro, é creditada ao rei Adoxa; no entanto, na bibliografia consultada sobre a história política do Onim não conseguimos aferir se "Adoxa" era um rei que sucedeu Ajan no comando daquele país ou se era uma das inúmeras denominações utilizadas a bel prazer pelos traficantes das diferentes nacionalidades que negociavam no Golfo do Benim para se referir a Ajan. Acreditamos que a segunda hipótese seja a correta, posto que, conforme dá conta a tradição oral, no período em questão Ajan, ou Adele como também aparece, era, de fato, o rei do Onim.

${ }^{5}$ Seguindo a tradição das relações afro-luso-brasileiras, uma vez interrompida a continuidade da embaixada de Onim por decisão unilateral do governo imperial brasileiro, a bengala foi devolvida a Manoel Alves de Lima para que pudesse devolvê-la a Ajan (AHI, 273/1/13). Para maiores informações quanto ao papel simbólico e político desse objeto na história das relações afro-luso-brasileiras ver SOARES (2014, p. 252-256).

${ }^{6}$ Isto tomando por base que 1 tostão equivalia, ao tempo do Império, a 80 réis (AMATO, NEVES, RUSSO, 2012).

${ }^{7}$ De fato, a concessão das passagens foi solicitada por Manoel de Alves Lima como dá conta uma carta sua dirigida ao ministro dos Negócios Estrangeiros, que aparenta ser de finais de 1824 (AHI, 273/1/13).

${ }^{8}$ A França representada pelo conde de Gestas e a Grã-Bretanha por Chamberlain.

${ }^{9}$ O prognóstico em questão (de 1847) era assinado por Bento da Silva Lisboa, barão de Cairu, e fora endereçado ao representante britânico naquele tempo no Rio, Lord Hudson (BETHELL, 2002, p. 330). 
A última embaixada de um monarca africano no Brasil...

\section{Referências}

AMATO, Claudio; NEVES, Irlei S.; RUSSO, Arnaldo. Livro das moedas do Brasil: 1643 a 2012. 13 ed. São Paulo: Stampato, 2012.

ARAÚJO, Ana Lucia. Dahomey, Portugal and Bahia: king Adandozan and the Atlantic Slave Trade. Slavery and abolition: a journal of Slave and Post-Slave studies, Londres, vol. 33, n. 1, p. 1-19, 2011.

BETHELL, Leslie. A abolição do comércio brasileiro de escravos: A Grã-Bretanha, o Brasil e a questão do comércio de escravos, 1807-1869. Brasília: Senado Federal, 2002.

CALÓGERAS, João Pandiá. A política exterior do Império. v. 2. O Primeiro Reinado. Brasília: Senado Federal, 1998.

CERVO, Amado; MAGALHÃES, José Calvet de. Depois das caravelas: as relações entre Portugal e Brasil: 1808-2000. Brasília: Editora da UnB, 2000.

FAZENDA, José Vieira. Antiqualhas e memórias do Rio de Janeiro. parte 5. Revista Trimestral do Instituto Histórico e Geográfico Brasileiro, Rio de Janeiro, tomo 93, v. 147, 1923.

KRAAY, Hendrik. Muralhas da independência e liberdade do Brasil: a participação popular nas lutas políticas (Bahia, 1820-25). In: MALERBA, Jurandir (Org.). A independência brasileira: novas dimensões. Rio de Janeiro: Editora FGV, 2006. p. 303-340.

LARA, Silvia Hunold. Uma embaixada africana na América portuguesa. In: JANCSÓ, István; KANTOR, Iris (Org.). Festas: cultura e sociabilidade na América portuguesa. v. 1. São Paulo: IMESP; Edusp; Hucitec; FAPESP, 2001. p. 151-165.

. Fragmentos setecentistas: escravidão, cultura e poder na América portuguesa. São Paulo: Companhia das Letras, 2007.

LAW, Robin. The dynastic chronology of Lagos. Lagos Notes and Records, Lagos, v. 2, n. 2, 1968.

. Trade and politics behind the Slave Coast: the Lagoon Traffic and the rise of Lagos, 1500-1800. The journal of African history, Cambridge, v. 24, n. 3, p. 321-348, 1983.

MANN, Kristin. Slavery and the birth of an African city: Lagos, 1760-1900. Bloomington: Indiana University Press, 2007.

NEVES, Lúcia M. Bastos P. Estado e política na independência. In: GRINBERG, Keila; SALLES, Ricardo (Org.). O Brasil Imperial. v. 1. 1808-1831. Rio de Janeiro: Civilização Brasileira, 2009. p. 95-136.

Anos 90, Porto Alegre, v. 22, n. 42, p. 325-351, dez. 2015 
Reconhecimento da independência do império do Brasil pelos reis d’África. Revista Trimestral do Instituto Histórico e Geográfico Brasileiro, Rio de Janeiro, tomo 54, parte 2, p. 161-162, 1891.

RODRIGUES, Jaime. O tráfico de escravos e a experiência afro-luso-brasileira: transformações ante a presença da corte portuguesa no Rio de Janeiro. Anos 90, Porto Alegre, vol. 15, n. 27, p. 107-123, jul. 2008.

SCWARCZ, Lilia Moritz. As barbas do imperador: D. Pedro II, um monarca nos trópicos. São Paulo: Companhia das Letras, 1998.

SILVA, Alberto da Costa e. Um rio chamado Atlântico: A África no Brasil e o Brasil na África. Rio de Janeiro: Nova Fronteira; Editora da UFRJ, 2003.

. Francisco Félix de Souza, mercador de escravos. Rio de Janeiro: Nova Fronteira; Editora da UERJ, 2004.

. Cartas de um embaixador de Onim. Cadernos do CHDD, Brasília, ano 4, n. 6, p. 195-205, 1. sem. 2005.

SMITH, Robert Sydney. The Lagos Consulate, 1851-1861. Londres: The Macmillan Press; Lagos: The University of Lagos Press, 1978.

SOARES, Mariza de Carvalho. Trocando galanterias: a diplomacia do comércio de escravos, Brasil-Daomé, 1810-1822. Afro-Ásia, Salvador, n. 49, p. 229-271, jun. 2014.

VERGER, Pierre. Fluxo e refluxo do tráfico de escravos entre o Golfo de Benim e a Bahia de Todos os Santos: dos séculos XVII a XIX. São Paulo: Corrupio, 1987.

Recebido em: 18/04/2015

Aprovado em: 01/07/2015 